\title{
The ReAVA Project: Assessment of the Potential Alkali-Reactivity of Volcanic Aggregates from Azores Islands
}

\author{
Sara Medeiros, João Carlos Nunes, Tetsuya Katayama, Isabel Fernandes, \\ António Santos Silva, Vidália Miranda, and Dora Soares
}

\begin{abstract}
Volcanic rocks have been found to be potentially alkali-reactive in a number of countries, including Japan, New Zealand, Iceland and Turkey. In order to characterize the potential reactivity of the volcanic rocks in Azores a project is being carried out, under the support of the Azores Government: the ReAVA Project- “Characterization of Potential Reactivity of the Volcanic Aggregates from the Azores Archipelago: Implications on the Durability of Concrete Structures". This project comprises mainly: (1) petrographic assessment of the aggregates, (2) assessment of their performance in expansion tests and (3) site inspection of existing large concrete structures. This study has also the support of the IMPROVE Project- "Improvement of Performance of Aggregates in the Inhibition of Alkali-Aggregate Reactions in Concrete", aiming to minimize the occurrence of alkali aggregate reaction (AAR) in Portugal. The Azorean rocks used as aggregates are mainly basalts and some trachytes. The reactivity of this kind of rocks is usually associated with the presence of volcanic glass, altered minerals and $\mathrm{SiO}_{2}$ content of the rock. The petrographic examinations of the rocks confirmed that one of the basaltic samples contains volcanic glass. The occurrence of microcrystalline quartz as a secondary product filling the interstices of the trachyte sample was confirmed by scanning electron microscope. The results of the concrete expansion test RILEM AAR-3 showed an increasing expansion starting on 140 days and continued to grow after 2 years of laboratory testing, but below the limit of $0.05 \%$ recommended for this method.
\end{abstract}

Keywords

Azores • Volcanic aggregates • Petrography • Expansion tests

S. Medeiros $(\bowtie) \cdot$ J. C. Nunes

Departamento de Geociências, Universidade Dos Açores, Ponta

Delgada, Azores, Portugal

e-mail: saramedeiros@uac.pt

T. Katayama

Taiheiyo Consultant Co. Ltd, Sakura, Japan

I. Fernandes

Universidade Do Porto, DGAOT/Centro de Geologia, Porto,

Portugal

e-mail: ifernand@fc.up.pt

A. Santos Silva · D. Soares

Laboratório Nacional de Engenharia Civil, Lisbon, Portugal

e-mail: ssilva@lnec.pt

V. Miranda

Laboratório Regional de Engenharia Civil, Ponta Delgada, Azores,

Portugal

\subsection{Introduction}

The Azores archipelago is the most occidental region of Portugal and consists of nine volcanic islands located in the North Atlantic Ocean. Here, volcanic rocks, mainly those of basaltic nature, have been widely used as aggregates for concrete purposes. The archipelago magmatism belongs to the alkaline series with compositional characteristics that range from basalts to trachytes. Santa Maria Island is the oldest island of the archipelago with 8.12 Ma.

The deterioration of concrete by alkali silica reaction (ASR) is well known in several countries like Japan, Iceland and Turkey. In Portugal, the only information about the alkali performance of volcanic rocks is related to the study of 